\title{
The Handbook of Antagonism
}

Conceptualizations, Assessment,

Consequences, and Treatment of the Low End of Agreeableness

Joshua D. Miller

Professor

Department of Psychology, University of Georgia, Athens, Georgia, United States

\section{Donald R. Lynam}

Professor

Department of Psychological Sciences, Purdue University, West Lafayette, Indiana, United States 


\title{
Agreeableness, antagonism, and mental health across cultures
}

\author{
Amber Gayle Thalmayer, Jérôme Rossier \\ Research Center in Vocational Psychology and Career Counseling, Institute of Psychology, \\ University of Lausanne, Lausanne, Switzerland
}

Knowing whether a psychological phenomenon occurs across cultures is important for understanding the interplay between individuals and their cultural context. For example, learning that bulimia nervosa is specific to recent times and Western industrialized cultures (Keel \& Klump, 2003), that the long-term prognosis for schizophrenia patients is worse in such cultures compared to developing nations (e.g., Leff, Sartorius, Jablensky, Korten, \& Ernberg, 1992), or that hikikomori (extreme social withdrawal; Furlong, 2008) is a manifestation of anxiety specific to the Japanese cultural context lends insight to the challenges a culture may create. On the other hand, comparable syndromes of depression, bipolar disorder, and schizophrenia around the world inform us about universal vulnerabilities of the human psyche, although prevalence, symptoms, and beliefs about etiology can vary considerably, with important implications for locally relevant assessment and treatment (Tseng, 2001).

Posing questions about the culturally specific versus universal aspects of a psychological phenomenon is therefore important, but answering them can be complex. For one thing, simply importing personality measures or diagnostic criteria can preclude learning from the new culture. While such studies may provide evidence of replicable constructs, they cannot identify culture-specific ones, which may have better predictive and explanatory power (Cheung, van de Vijver, \& Leong, 2011). Even when a construct has been deemed appropriate for import, measures and methods may need to be adapted to achieve equivalence in how they are perceived. Direct translation of terms such as proud or anxious, for example, can lead to different responses due to differing emotional/evaluative meanings (Thalmayer \& Saucier, 2014). And when using a subjective scale such as degree of agreement about how "friendly" or "orderly" one is, one must compare oneself to well-known others, leading to potential reference group effects (Heine, Buchtel, \& Norenzayan, 2008).

The core premise of personality psychology, that internal traits explain behavior, was developed in a Western context (Cross \& Markus, 1999). While terms for personality differences are used universally across cultures (Saucier, Thalmayer, \& BelBahar, 2014), internal qualities may not be given the same causal significance everywhere. In some settings, roles, relationships, and obligations may be seen as larger influences on behavior (Cross \& Markus, 1999). Relatedly, cultures differ on whether personality attributes are seen as fixed and enduring and the extent to which this is valued. In individualistic cultures, personality consistency is associated with social 
skills, well-being, and being well-liked (Suh, 2002). But in collectivistic cultures, behaving similarly regardless of context may be viewed as a lack of self-control, social skills, and maturity (Suh, 2002). In traditional cultures, many social contexts are largely scripted, demanding less variation and expression of individual psychological differences (Cross \& Markus, 1999). The relative importance of personality in selfdefinition is therefore influenced by the cultural context. And in terms of mental disorders, Paris and Lis (2013) describe ways that culture and historical context can shape clinical presentation, for example, in terms of the locally understood symptoms and presentations, or "symptom bank," from which individuals subconsciously choose how to communicate their dysphoria to others, and in terms of local stressors or protective factors that can determine whether vulnerabilities become disorders.

The aim of this chapter, however, is to review and assess the best available evidence on the associations between Agreeableness/antagonism and mental health across cultures. Given contemporary migration flow and shifting demographics, it is important to consider whether our knowledge about these traits and conditions can be used with people and patients from backgrounds and contexts outside the mainstream of Western, industrialized cultures. Moreover, knowing if the traits and conditions in question are more timeless, universal vulnerabilities of the human psyche, or instead recent phenomenon specific to a cultural time and place is still an open question, which we will try to address in this chapter.

\section{Agreeableness/antagonism across cultures}

The personality dimension of Agreeableness, along with the rest of the Big Five, was defined by consistent patterns in personality inventories and models in use in the early part of the 20th century, by lexical studies of personality in English (Saucier \& Goldberg, 2001), and by the Five-Factor Model of Costa and McCrae (1992). Models including an Agreeableness dimension were then replicated in many cultures in the 1990s and early 2000s (e.g., Saucier \& Goldberg, 2001). Several large-scale studies have administered Big Five inventories across cultures. Peer ratings on the revised NEO Personality Inventory (NEO-PI-R; Costa \& McCrae, 1992) were collected in 50 cultures (McCrae et al., 2005a) and mean profiles of self-ratings from 62 cultures were compared (Allik et al., 2017). Findings support the interpretability of this dimension and the model's structure, and differences between countries are consistently smaller than differences within countries. Although cross-cultural mean differences for Agreeableness are small and cannot yet be considered reliable (Church et al., 2011), many studies report slightly higher Agreeableness in collectivist societies (e.g., Rossier, Dahourou, \& McCrae, 2005), though individualism appears to correlate more consistently with higher Extraversion than lower Agreeableness (McCrae et al., 2005b). Cross-cultural studies of personality inventories, however, have not yet been able to present evidence of scalar measurement invariance among cultures separated by large cultural distance, which would indicate reliability and validity for comparing mean scores across cultures (Church et al., 2011; Rossier, Ouedraogo, \& Dahourou, 2017; Thalmayer \& Saucier, 2014). This has been true for the Big Five Inventory 
(BFI) in 56 nations (Schmitt, Allik, McCrae, \& Benet-Martínez, 2007), and to a forager-farmer group in the Amazon (Gurven, Von Rueden, Massenkoff, Kaplan, \& Lero Vie, 2013), and the closely related Big Six model using the Questionnaire Big Six (QB6) in 26 countries (Thalmayer \& Saucier, 2014), as well as the NEOPI-R. Thus it is not yet possible to trust that a person who receives a low score on Agreeableness on the inventory in Thai, for example, is really less Agreeable than someone with a high score in Swahili.

Indeed, a number of measurement issues must be considered. For example, reference group effects, as noted previously, may lead people to rate themselves against different standards. This would explain why Mexicans describe themselves as less sociable than North Americans, despite displaying more sociable behavior (Ramírez-Esparza, Mehl, Álvarez-Bermúdez, \& Pennebaker, 2009). Students in schools with high standards achieve more, but have lower academic self-concepts than lower achieving students in less challenging contexts (Van de Gaer, Grisay, Schulz, \& Gebhardt, 2012). Heine et al. (2008) found indicators of high national Conscientiousness (e.g., postal workers' speed, per capita GDP, life expectancy) to be positively correlated with perceptions of national character, but negatively with national mean Conscientiousness scores. Mõttus, Allik, and Realo (2010), on the other hand, show that such correlations become more intuitive when explored at the facet level and make a case for the future of national mean comparisons. The interplay between traits and sociocultural context, however, means that measurement issues are complex.

Studies using "emic" approaches, which build personality models from the ground up in a given locale, provide evidence for other relevant models and traits, information which can be obscured by reliance on an imported inventory. For example, Ashton et al. (2004) and Saucier (2009) showed that a six-factor model, including a factor related to honesty and moral character, better fit the cumulative results from a combined total of 14 indigenous lexical studies. These efforts have the advantage of building a culture-fair model, rather than simply testing replicability of a North American model. High Agreeableness in the Big Six focuses on conflict avoidance; low Agreeableness emphasizes reactive aggression, impatience, and hostility, whereas low Honesty/Propriety encompasses instrumental aggression, intentionally taking advantage of others (Thalmayer \& Saucier, 2014). This distinction could be especially interesting regarding the externalizing syndromes of interest in this volume.

Other recent work continues to go further afield. Indigenous lexical studies in two of Africa's four main language groups, East African Maasai and West Africa SupyireSenufo, led to a common four-dimensional structure, with factors tentatively labeled Anger, Laziness, Virtue, and Happiness; anger correlates moderately with Big Five and Six Agreeableness (Thalmayer, Saucier, Ole-Kotikash, Payne, \& Carlson, 2018). The South African Personality Inventory (SAPI) project comprised extensive efforts to develop an indigenous inventory "culture fair" to the country's 4 ethnic and 11 language groups (Fetvadjiev, Meiring, van de Vijver, Nel, \& Hill, 2015). The resulting inventory includes six dimensions, four of which overlap with Big Five domains, with the exception of Agreeableness-Social Relations-Positive, and Negative seem conceptually related to Big Five Agreeableness, but are not highly correlated with it (.13 and .20; Fetvadjiev et al., 2015). A similar emic-etic approach used 
qualitative analyses of person descriptions to develop a personality questionnaire suited to spoken Arabic in the Levant (Zeinoun, Daouk-Öyry, Choueiri, \& Van de Vijver, 2017). The resulting indigenous seven-factor model largely included the Big Five, including Agreeableness/Soft Heartedness (Zeinoun et al., 2017). Studies comparing emic and etic dimensions have shown that indigenous scales, for example, Interpersonal Relatedness in an emic Chinese personality inventory, can better predict life, work, and mental health outcomes than imported scales (Cheung, Cheung, \& Fan, 2013; Sanchez-Burks, Nisbett, \& Ybarra, 2000; Zeinoun et al., 2017).

As a starting point in exploring cross-cultural evidence for the relation of antagonism to mental health, we can conclude that a factor with the basic outlines of Agreeableness versus antagonism is measurable across cultures, and it arises in local emic studies in many cases. Findings from emic work, however, suggest that while an interpersonal domain may be universally relevant to personality conceptions, locally salient content may differ.

\section{Gender and Agreeableness across cultures}

Several etic studies report gender differences across cultures. In Western countries on both self- and peer-ratings, men consistently score higher than women on Assertiveness and lower on Agreeableness and Neuroticism (Costa, Terracciano, \& McCrae, 2001; McCrae et al., 2005a; Schmitt, Realo, Voracek, \& Allik, 2008). They also may score lower on Conscientiousness (Schmitt et al., 2008) and Openness to Feelings and higher on Openness to Ideas (Costa et al., 2001; McCrae et al., 2005a). These appear to be some of the most robust psychological differences between the sexes-while smaller than those for mate preferences, sexual behaviors, or physical strength, they appear larger and more consistent than differences in cognitive ability, attributional style, or self-esteem (Schmitt et al., 2008).

Sex differences on Agreeableness and Neuroticism are not surprising given gender stereotypes and the higher prevalence of mental disorders related to antagonism among men. More counterintuitive is the fact that they are consistently larger in Western, industrialized countries with higher gender equity; sex differences in Asia and Africa are consistently smaller, as is overall personality variation among men (Costa et al., 2001; McCrae et al., 2005b; Schmitt et al., 2008). This is contrary to patterns of sexual differentiation in other psychological variables, where sex differences are smaller in cultures with higher gender equity and standards of living (Schmitt et al., 2008).

Hypotheses explored by Schmitt et al. (2008) for this finding include social desirability biases, frames of reference, attribution processes, and measurement error, but they conclude that the evidence best supports the "evolutionary mismatch perspective." This posits that where contemporary environments differ more from the hunter-gatherer environments in which humans evolved, the development of psychological sex differences is attenuated. Sex-related differences are assumed to exist in domains where the sexes faced different adaptive problems during evolutionary history. If modern nation-states are psychologically closer to hunter-gatherer cultures, then such sex differences may be given fuller expression (Schmitt et al., 2008). While 
contrary to results for other psychological variables, this is analogous to sex differences in height and blood pressure, which are attenuated in less developed, agricultural-based societies; even within cultures, sex differences in height are larger for better-off groups, because boys grow taller. Indeed, in the same group of industrialized, egalitarian countries, men had higher blood pressure than women, whereas in less developed countries blood pressure was practically identical (Schmitt et al., 2008).

This interesting hypothesis, however, assumes homogeneity in early human societies. Work with ethnographic literature (e.g., Harpending \& Draper, 1988) demonstrates an association between male aggressiveness and whether local conditions require long-term paternal investments. Individualistic, industrialized societies have conditions where cooperation is not essential to survival and more rewards may accrue to those who compete fiercely, leading to lower scores in Agreeableness for men. This may also be true among some traditional societies. And as discussed previously, in collectivistic cultures, behavior may be determined less by personality traits are more by social context (Rossier et al., 2005), which could explain smaller variation and lower gender differences in collectivistic cultures. Whatever their source, these differences are relevant to the question at hand, in part by indicating ways that personality dimensions are influenced by cultural setting. They also suggest that gender differences in the prevalence of mental health conditions related to low Agreeableness are likely to be larger in Western cultures, and that such conditions are likely to more prevalent here.

\section{Change in Agreeableness over the lifespan across cultures}

Cross sectional studies of Big Five traits consistently demonstrate higher scores on Agreeableness, Conscientious, and Emotional Stability, and sometimes lower scores on Extraversion and Openness for older adults compared to younger ones (e.g., Donnellan, Hill, \& Roberts, 2015). A meta-analysis of longitudinal studies replicated these findings, showing that individuals increase in Conscientiousness, Emotional Stability, and social dominance (Extraversion) in young adulthood, then later increase in Agreeableness and decrease in social vitality (Extraversion) and Openness (Roberts, Walton, \& Viechtbauer, 2006). Bleidorn et al. (2013) replicated these findings in 62 countries using the BFI. Across nations, Emotional Stability, Extraversion, Openness, Agreeableness, and Conscientiousness tended to increase from early to middle adulthood. Consistent with social investment theory, the team found that personality maturation occurred earlier in cultures with an earlier onset of adult-role responsibilities. Interestingly, the authors found that it was transition to the labor force, rather than family-role transitions such as marriage or parenthood, that predicted "maturation." They note that while this is contrary to some assumptions of social investment theory, it is consistent with lay beliefs. For example, Arnett (2001) found that American adolescents and adults considered becoming financially independent a stronger indicator of adult status than marriage or parenthood. These results suggest that opportunities for young people to integrate into meaningful social roles and economic independence can foster an increase in Agreeableness and presumably reduce disorders related to antagonism. 


\section{Agreeableness/antagonism relations to mental health}

The mental disorders, symptoms, and behaviors known to correlate with antagonism in North America and other Western countries are reviewed later for cross-cultural evidence.

\section{Childhood aggression and conduct disorder}

Canino, Polanczyk, Bauermeister, Rohde, and Frick (2010) conducted a systematic review of cross-cultural evidence on conduct disorder (CD) and oppositional defiant disorder (ODD) to inform the American Psychiatric Association's Diagnostic and Statistical Manual of Mental Disorders, Fifth Edition (DSM-V) classifications. Cultural factors should play a role in the prevalence of these disorders due to their association with risk and protective factors like prenatal care, infant nutrition, neighborhood safety, and family environment, attachments, and supervision. Prevalence rates can also be impacted by cultural setting because symptoms may be differentially viewed as dysfunctional. The team, however, found similar prevalence rates for CD $(3.2 \%)$ and ODD (3.3\%) across 25 published studies using DSM criteria, primarily from North America and Europe. This indicates a reasonable basis for these conditions across Western societies, though they note that using DSM criteria likely increased homogeneity and that symptoms should be validated against external and clinical criteria (Canino et al., 2010).

More generally, parenting practices have been shown to relate to degree of aggression expressed by children, especially boys (e.g., Ekblad, 1988), for example, comparing American to Thai children (Weisz, Suwanlert, Chaiyasit, \& Walter, 1987). Child Behavior Checklist scores in 16 regions indicated higher rates of internalizing and lower of externalizing syndromes in Asian compared to Western countries (Crijnen, Achenbach, \& Verhulst, 1999). Children are certainly influenced by familial and cultural settings in the ways they express unhappiness and frustration, and whether these will include behaviors defined as aggressive, oppositional, or disordered.

\section{Aggression}

Cooke (1996) provided a review of aggressive behavior across cultures, citing evidence for substantial variation. Some groups, for example, the Inuit of the Artic, the Pygmies of Africa, and Mennonite and Amish communities in North America, rarely use violence, while others, for example, the Yanomami of the Upper Amazon, express physical and verbal aggression on a daily basis. Cultural socialization plays a significant role in whether and how aggression is expressed.

To expand psychologists' understanding of aggression beyond Western societies, Severance et al. (2013) used multidimensional scaling analyses of ratings on acts of aggression to explore perceptions between four cultures varying in "cultural logic" (Leung \& Cohen, 2011). In Japan, a culture of face, self-worth stems from the views others hold, status in the hierarchy, and humility, modesty, and self-control. In this 
interdependent context, maintaining harmony with the group is central, and conflict is handled indirectly (Leung \& Cohen, 2011). There is strong differentiation between direct and passive aggression, but because violence is rare, verbal aggression that can damage reputation is seen as direct; because aggressive acts can seriously damage someone's self-worth, such acts are viewed as extremely immoral and callous (Severance et al., 2013).

In Pakistan, a culture of honor, maintaining a reputation for strength is paramount. The collectivistic context means that shame for close others is experienced as highly personal. In the United States, the South has been shown to be a culture of honor, but the majority culture is one of dignity: Individuals are believed to have intrinsic worth which cannot easily be lost. Self-evaluations are most important, and the individualistic context means that close others are not strongly reflective on the self. Israel, a multicultural country combining Middle Eastern and European influences and value systems, embodies a mix of honor and dignity cultures (Leung \& Cohen, 2011; Severance et al., 2013).

In Pakistan and Israel, being the object of an aggressive act is perceived as humiliating, a threat to honor and social status, indicating the danger of social exclusion in clan-based social systems. In Pakistan, verbal aggression is perceived as especially threatening, perhaps because in a culture of honor, verbal declarations become obligations. In the United States, other's aggression is less relevant to one's selfworth. Instead, infringements on material belongings or professional accomplishments, by extension on one's autonomy, are perceived as especially damaging. This is salient also in Israel, where gossip and public insults are also considered threatening to personal resources. Here more than elsewhere, verbal acts targeting one's family are perceived as direct threats (Severance et al., 2013). Relatedly, childhood maltreatment had a stronger impact on the development of later personality disorders (PDs) in Togo compared to France (Kounou et al., 2015). These cultural differences in how aggression and antagonism are communicated and perceived indicate the necessity of cultural knowledge when assessing individual behavior or traits.

\section{Antisocial personality disorder, psychopathy, and criminal behavior}

There is reason to believe that individuals with behavior patterns similar to psychopathy and antisocial personality disorder (ASPD) have existed across time and cultural settings. Murphy (1976) provides evidence for comparable syndromes among two nonindustrialized groups, aranakan among the Yoruba of Nigeria, and kunlangeta for Inuit Eskimos. Both syndromes describe persons who take advantage of others consistently and remorselessly, are unresponsive to social pressure or punishment, and are considered untreatable and unlikely to change. Sullivan and Kosson (2006) review historical examples, including a description of the Athenian general Alcibiades as a psychopath, and the reckless, cynical Trickster figures that appears across many cultures. 
There are also reasons to expect prevalence to vary across cultures. Social norms and values may allow or even encourage behavior that ultimately fits a pattern of disorder. Individualistic societies are more likely than collectivistic ones to allow the development of ASPD symptoms, including irresponsibility, callousness, lack of remorse, glibness and superficiality, grandiosity, and promiscuity (Cooke, 1996; Cooke, Michie, Hart, \& Clark, 2005). Harpending and Draper (1988) provide ethnographic evidence that aggressive and antisocial traits are more common in cultures where male competitiveness is high and parental effort low; where parental effort is high, such traits will be less common, as there are fewer rewards, and antisocial persons will be detected and ostracized. Indeed, rates of ASPD appear to be 10 times lower in Taiwan than in the United States (Compton et al., 1991).

The cross-cultural validity of psychopathy has been supported by studies importing the Psychopathy Checklist-Revised (PCL-R) to European countries (Cooke et al., 2005). Of the inventories three factors-deficient affective experience, arrogant and deceitful interpersonal style, impulsive and irresponsible behavioral style-the first appears to be the cross-cultural core of the construct, perhaps due to varying socialization across cultures, which may differentially interact with the core affective temperament to produce more or less pathological interpersonal and behavioral patterns (Cooke et al., 2005). In the same countries, Sullivan and Kosson (2006) report cross-Atlantic construct validity of psychopathy in terms of replicable positive associations with PD diagnoses, especially ASPD, secondarily with other Cluster B disorders; substance abuse; earlier initiation of criminal behavior; recidivism; rule infractions; and traits of impulsivity, aggression, and sensation seeking. North American prison populations typically have higher mean PCL-R scores, previously attributed to a lower prevalence of psychopathy in Europe due to cultural socialization. But another possibility is differences in criminal justice systems. In some nations, persons with psychopathic disorder are placed in mental hospitals rather than prisons. In others, incarceration rates are low. In Norway, the rate is 10 times lower than in the United States; only severe offenders are imprisoned, and nearly half the prison population meets criteria for psychopathy (Sullivan \& Kosson, 2006). A recent study of incarcerated women in South Africa also found psychopathy to be particularly associated with Cluster B PDs (Botha, Louw, \& Loots, 2017).

\section{Borderline and other personality disorders}

Although clinicians outside North America are less likely to make PD diagnoses, the constructs are comprehensible once imported (e.g., Paris \& Lis, 2013). The Personality Disorder Questionnaire and Interview had acceptable psychometric properties in Chinese (Yang et al., 2000), and the International Personality Disorder Examination had acceptable interrater reliability and temporal stability in samples of clinical patients from cities across North America, Europe, Africa, and Asia (Loranger et al., 1994), a study that found Borderline Personality Disorder (BPD) especially prevalent. The inventory structure was also stable in a sample of French-speaking African countries, 
and when translated into Mooré, and administered by interview to villagers in Burkina Faso (Rossier, Ouedraogo, Dahourou, Verardi, \& Meyer de Stadelhofen, 2013). Though thresholds for impairment may vary, there are surely individuals who "deviate markedly from the expectations of their culture" in every society (Tseng, 2001).

Paris and Lis (2013) argue that social risk factors, including modernity's disruptions to family structures, influence whether the traits that underlie PDs lead to disordered behavior-people with impulsivity and affective instability exist everywhere, but psychosocial risk or protective factors can determine whether their expression becomes pathological. Sociocultural factors are key to determining whether an individual's vulnerabilities create difficulties in meeting social expectations, a defining feature of PDs, and the "symptom bank" that will be drawn on. Specifically, patients in traditional societies are more likely to report internalizing problems than to exhibit self-harm and para-suicide, which are increasingly prevalent in the west, suggesting susceptibility to cultural factors (Paris \& Lis, 2013). Miller (1996), however, argues that many culture-specific disorders define individuals who, like those with BPD, perceive themselves as unable to meet social expectations and who express their resulting distress in culturally relevant ways.

\section{Substance use}

In samples from Mexico, Germany, the Netherlands, Canada, and the United States including a sample of Mexican-Americans, Merikangas et al. (1998) report similar prevalence of disordered substance use and comorbidity with mood and anxiety disorders, CD, and ASPD. They conclude that a consistent relationship between number of comorbid disorders and substance use severity, especially for drugs, indicates a common link between psychopathology and substance disorders, despite cultural variation in substances available and normal usage. Bennett, Janca, Grant, and Sartorius (1993) conducted interviews with community members from cultures that traditionally include social drinking and those that do not, and document consistencies in perceptions of problem drinking, including drinking alone and in large quantities, despite differences in normal use.

Heath (2001) and Martin, Chung, and Langenbucher (2014) review substance use and abuse over time and across cultures. Substance use appears to be a human universal, with alcohol fermentation and use of psychoactive plants extending to distant history and nonhuman animals. Heath (2001) argues that the experience, behaviors, and dangers of addiction with a given substance are defined by goals-medical, ritual, social, self-development, or recreational-and expectations. Social disapproval, and thus the definition of disordered use, varies culturally in ways not always consistent with actual dangers. Social consequences are also inconsistent, for example, the disproportionate punishment of Black users of crack cocaine in the United States, despite more widespread use of powdered cocaine among White users in the same period (Heath, 2001). Martin et al. (2014) point out that while compulsive use coupled with dysfunctions in reward, motivation, and affective systems clearly constitutes dysfunction, the point at which this is considered harmful has not been well defined by 
DSM criteria and varies across cultures. Thus while it appears likely that disordered substance use co-occurs with disorders related to antagonism across cultures, substance abuse can be hard to distinguish from use, especially without cultural knowledge, and thus may be a less dependable indicator.

\section{Summary and conclusions}

Agreeableness versus antagonism is a personality dimension that was defined first in North American cultures, but which corresponds to a reasonable degree with dimensions found in many other cultural settings. Studies translating Western measures into new languages have found that respondents in other cultural settings respond to Agreeableness items in similar ways, allowing a similar factor structure to emerge. There is not yet evidence for full measurement invariance of any personality measures in translation, thus there is not strong support for comparing mean scores across cultures, but such studies were reviewed. Of interest are findings that gender differences in Agreeableness, lower average scores for men, are more pronounced in industrialized nations with greater gender equity. Also of interest was the finding that Agreeableness appears to increase consistently across cultures with age, especially in the context of taking on financial responsibilities.

The disorders associated with antagonism also generally appear to exist across diverse cultural settings. A syndrome that matches psychopathy has been reported far back in time and across varied cultural settings. All human populations may include callous individuals who take advantage of others. Rates and types of aggressive behavior, however, vary considerably depending on local socialization processes, and thus associated disorders appear to be more common in the individualistic, industrialized west.

Future research of interest would include combined emic-etic studies of mental disorders in diverse cultures, in order to compare prevalence while also exploring local expressions of malaise. If the disorders described here are reliably less prevalent in more collectivistic, interdependent, and tight cultures, it would be useful to attempt to isolate cultural practices that could be imported to reduce antagonism. It would also be important to assess trade-offs in lower prevalence, for example, higher rates of internalizing syndromes. Similarly, if treatments vary in efficacy, the most effective could be tested for applicability to new contexts. Understanding that individualism, a dominant cultural value in Western cultures, likely increases antagonism, can help us understand the "shadow side" of the personal freedom and individualistic values we enjoy. Taking a fuller range of risks and benefits into account, we may find ways to temper the values we transmit to our children with appropriate concern for the feelings and the autonomy of others.

\section{Acknowledgment}

The contribution of Jérôme Rossier benefited from the support of the Swiss National Centre of Competence in Research LIVES — Overcoming vulnerability: Life course perspective, financed by the Swiss National Science. 


\section{References}

Allik, J., Church, A. T., Ortiz, F. A., Rossier, J., Hřebı'čková, M., de Fruyt, F., et al. (2017). Mean profiles of the NEO personality inventory. Journal of Cross-Cultural Psychology, 48, 402-420. https://doi.org/10.1177/0022022117692100.

Arnett, J. J. (2001). Conceptions of the transition to adulthood: perspectives from adolescence through midlife. Journal of Adult Development, 8, 133-143. https://doi.org/10.1023/ A: 1026450103225.

Ashton, M. C., Lee, K., Perugini, M., Szarota, P., De Vries, R. E., Di Blas, L., et al. (2004). A six-factor structure of personality-descriptive adjectives: solutions from psycholexical studies in seven languages. Journal of Personality and Social Psychology, 86, 356-366. https://doi.org/10.1037/0022-3514.86.2.356.

Bennett, L. A., Janca, A., Grant, B. F., \& Sartorius, N. (1993). Boundaries between normal and pathological drinking: a cross-cultural comparison. Alcohol Research and Health, 17(3), 190.

Bleidorn, W., Klimstra, T. A., Denissen, J. J., Rentfrow, P. J., Potter, J., \& Gosling, S. D. (2013). Personality maturation around the world: a cross-cultural examination of socialinvestment theory. Psychological Science, 24, 2530-2540. https://doi.org/ $10.1177 / 0956797613498396$.

Botha, R., Louw, D., \& Loots, S. (2017). Psychopathy and its relation to personality psychopathology in a South African female forensic context. South Africa Journal of Psychology https://doi.org/10.1177/0081246317715351.

Canino, G., Polanczyk, G., Bauermeister, J. J., Rohde, L. A., \& Frick, P. J. (2010). Does the prevalence of CD and ODD vary across cultures? Social Psychiatry and Psychiatric Epidemiology, 45, 695-704. https://doi.org/10.1007/s00127-010-0242-y.

Cheung, F. M., Cheung, S. F., \& Fan, W. (2013). From Chinese to cross-cultural personality inventory: a combined emic-etic approach to the study of personality in culture. M. Gelfand, C. Y. Chiu, \& Y. Y. Hong (Eds.), Advances in culture and psychology (pp. 117-180). Vol. 3(pp. 117-180). New York, NY: Oxford University Press. https:// doi.org/10.1093/acprof:oso/9780199930449.003.0003.

Cheung, F. M., van de Vijver, F. J. R., \& Leong, F. T. L. (2011). Toward a new approach to the study of personality in culture. American Psychologist, 66, 593-603. https://doi.org/ 10.1037/a0022389.

Church, A. T., Alvarez, J. M., Mai, N. T., French, B. F., Katigbak, M. S., \& Ortiz, F. A. (2011). Are cross-cultural comparisons of personality profiles meaningful? Differential item and facet functioning in the Revised NEO Personality Inventory. Journal of Personality and Social Psychology, 101, 1068-1089. https://doi.org/10.1037/a0025290.

Compton, W. M., Helzer, J. E., Hwu, H. G., Yeh, E. K., McEvoy, L., Tipp, J. E., et al. (1991). New methods in cross-cultural psychiatry: psychiatric illness in Taiwan and the United States. American Journal of Psychiatry, 148, 1697-1704. https://doi.org/10.1176/ ajp.148.12.1697.

Cooke, D. J. (1996). Psychopathic personality in different cultures. What do we know? What do we need to find out? Journal of Personality Disorders, 10, 23-40. https://doi.org/10.1521/ pedi.1996.10.1.23.

Cooke, D. J., Michie, C., Hart, S. D., \& Clark, D. (2005). Searching for the pan-cultural core of psychopathic personality disorder. Personality and Individual Differences, 39, 283-295. https://doi.org/10.1016/j.paid.2005.01.004.

Costa, P. T., Jr., \& McCrae, R. R. (1992). Revised NEO Personality Inventory (NEO-PI-R) and NEO Five-Factor Inventory (NEO-FFI) professional manual. Odessa, FL: Psychological Assessment Resources. 
Costa, P., Jr., Terracciano, A., \& McCrae, R. R. (2001). Gender differences in personality traits across cultures: robust and surprising findings. Journal of Personality and Social Psychology, 81, 322-331. https://doi.org/10.1037/0022-3514.81.2.322.

Crijnen, A. A., Achenbach, T. M., \& Verhulst, F. C. (1999). Problems reported by parents of children in multiple cultures: the Child Behavior Checklist syndrome constructs. American Journal of Psychiatry, 156(4), 569-574.

Cross, S. E., \& Markus, H. R. (1999). The cultural constitution of personality. In L. A. Pervin \& P. O. John (Eds.), Handbook of personality (pp. 378-396). New York: Guilford.

Donnellan, M. B., Hill, P. L., \& Roberts, B. W. (2015). Personality development across the life span: current findings and future directions. M. Mikulincer, P. R. Shaver, M. L. Cooper, \& R. J. Larsen (Eds.), APA handbook of personality and social psychology (pp. 107-126). Personality processes and individual differences: Vol. 4, (pp. 107-126). . https://doi. org/10.1037/14343-005.

Ekblad, S. (1988). Influence of child-rearing on aggressive behavior in a transcultural perspective. Acta Psychiatrica Scandinavica, 78, 133-139. https://doi.org/10.1111/j.16000447.1988.tb09012.x.

Fetvadjiev, V. H., Meiring, D., van de Vijver, F. J., Nel, J. A., \& Hill, C. (2015). The South African Personality Inventory (SAPI): a culture-informed instrument for the country's main ethnocultural groups. Psychological Assessment, 27, 827-837. https://doi.org/ 10.1037/pas0000078.

Furlong, A. (2008). The Japanese Hikikomori phenomenon: acute social withdrawal among young people. The Sociological Review, 56, 309-325. https://doi.org/10.1111/j.1467954X.2008.00790.x.

Gurven, M., Von Rueden, C., Massenkoff, M., Kaplan, H., \& Lero Vie, M. (2013). How universal is the Big Five? Testing the five-factor model of personality variation among forager-farmers in the Bolivian Amazon. Journal of Personality and Social Psychology, 104, 354-370. https://doi.org/10.1037/a0030841.

Harpending, H., \& Draper, P. (1988). Antisocial behavior and the other side of cultural evolution. In T. E. Moffitt \& S. A. Mednick (Eds.), Biological contributions to crime causation. Boston, MA: Matinus Nijhoff.

Heath, D. B. (2001). Culture and substance abuse. Psychiatric Clinics, 24(3), 479-496. https:// doi.org/10.1016/S0193-953X(05)70242-2.

Heine, S. J., Buchtel, E. E., \& Norenzayan, A. (2008). What do cross-national comparisons of personality traits tell us? The case of conscientiousness. Psychological Science, 19, 309-313. https://doi.org/10.1016/S0193-953X(05)70242-2.

Keel, P. K., \& Klump, K. L. (2003). Are eating disorders culture-bound syndromes? Implications for conceptualizing their etiology. Psychological Bulletin, 129, 747-769. https://doi. org/10.1037/0033-2909.129.5.747.

Kounou, K. B., Dogbe Foli, A. A., Djassoa, G., Amétépé, L. K., Rieu, J., Mathur, A., et al. (2015). Childhood maltreatment and personality disorders in patients with a major depressive disorder: a comparative study between France and Togo. Transcultural Psychiatry, 52, 681-699. https://doi.org/10.1177/1363461515572001.

Leff, J., Sartorius, N., Jablensky, A., Korten, A., \& Ernberg, G. (1992). The International Pilot Study of Schizophrenia: five-year follow-up findings. Psychological Medicine, 22, 131-145.

Leung, A. K. Y., \& Cohen, D. (2011). Within-and between-culture variation: individual differences and the cultural logics of honor, face, and dignity cultures. Journal of Personality and Social Psychology, 100, 507-526. https://doi.org/10.1037/a0022151. 
Loranger, A. W., Sartorius, N., Andreoli, A., Berger, P., Buchheim, P., Channabasavanna, S. M., et al. (1994). The International Personality Disorder Examination: the World Health Organization/Alcohol, Drug Abuse, and Mental Health Administration international pilot study of personality disorders. Archives of General Psychiatry, 51(3), 215-224.

Martin, C. S., Chung, T., \& Langenbucher, J. W. (2014). Historical and cultural perspectives on substance use and substance use disorders. K. J. Sher (Ed.), The Oxford handbook of substance use and substance use disorders (pp. 29-49). Vol. 1(pp. 29-49). Oxford: Oxford University Press.

McCrae, R. R., Terracciano, A., \& 78 Members of the Personality Profiles of Cultures Project (2005a). Universal features of personality traits from the observer's perspective: data from 50 cultures. Journal of Personality and Social Psychology, 88, 547-561. https://doi.org/ 10.1037/0022-3514.88.3.547.

McCrae, R. R., Terracciano, A., \& 79 Members of the Personality Profiles of Cultures Project (2005b). Personality profiles of cultures: aggregate personality traits. Journal of Personality and Social Psychology, 89, 407-425. https://doi.org/10.1037/0022-3514.89.3.407.

Merikangas, K. R., Mehta, R. L., Molnar, B. E., Walters, E. E., Swendsen, J. D., AguilarGaziola, S., et al. (1998). Comorbidity of substance use disorders with mood and anxiety disorders: results of the International Consortium in Psychiatric Epidemiology. Addictive Behaviors, 23(6), 893-907. https://doi.org/10.1016/S0306-4603(98)00076-8.

Miller, S. G. (1996). Borderline personality disorder in cultural context: commentary on Paris. Psychiatry, 59(2), 193-195.

Mõttus, R., Allik, J., \& Realo, A. (2010). An attempt to validate national mean scores of Conscientiousness: no necessarily paradoxical findings. Journal of Research in Personality, 44, 630-640. https://doi.org/10.1016/j.jrp.2010.08.005.

Murphy, J. M. (1976). Psychiatric labelling in cross-cultural perspective. Science, 191(4231), 1019-1028.

Paris, J., \& Lis, E. (2013). Can sociocultural and historical mechanisms influence the development of borderline personality disorder? Transcultural Psychiatry, 50, 140-151. https:// doi.org/10.1177/1363461512468105.

Ramírez-Esparza, N., Mehl, M. R., Álvarez-Bermúdez, J., \& Pennebaker, J. W. (2009). Are Mexicans more or less sociable than Americans? Insights from a naturalistic observation study. Journal of Research in Personality, 43(1), 1-7. https://doi.org/10.1016/j. jrp.2008.09.002.

Roberts, B. W., Walton, K. E., \& Viechtbauer, W. (2006). Patterns of mean-level change in personality traits across the life course: a meta-analysis of longitudinal studies. Psychological Bulletin, 132, 1-25. https://doi.org/10.1037/0033-2909.132.1.1.

Rossier, J., Dahourou, D., \& McCrae, R. R. (2005). Structural and mean-level analyses of the five-factor model and locus of control: further evidence from Africa. Journal of CrossCultural Psychology, 36, 227-246. https://doi.org/10.1177/0022022104272903.

Rossier, J., Ouedraogo, A., \& Dahourou, D. (2017). Personality structure and assessment in French-speaking African cultures. T. Church (Ed.), The Praeger handbook of personality across cultures (pp. 73-104). Trait psychology across cultures: Vol. 1(pp. 73-104). Santa Barbara, CA: Praeger. Manuscript submitted for publication.

Rossier, J., Ouedraogo, A., Dahourou, D., Verardi, S., \& Meyer de Stadelhofen, F. (2013). Personality and personality disorders in urban and rural Africa: results from a field trial in Burkina Faso. Frontiers in Psychology, 4, 1-11. https://doi.org/10.3389/ fpsyg.2013.00079. 
Sanchez-Burks, J., Nisbett, R. E., \& Ybarra, O. (2000). Cultural styles, relationship schemas, and prejudice against out-groups. Journal of Personality and Social Psychology, 79, 174-189. https://doi.org/10.1037/0022-3514.79.2.174.

Saucier, G. (2009). Recurrent personality dimensions in inclusive lexical studies: indications for a Big Six structure. Journal of Personality, 77, 1577-1614. https://doi.org/10.1111/j.14676494.2009.00593.x.

Saucier, G., \& Goldberg, L. R. (2001). Lexical studies of indigenous personality factors: premises, products, and prospects. Journal of Personality, 69, 847-888. https://doi.org/ 10.1111/1467-6494.696167.

Saucier, G., Thalmayer, A. G., \& Bel-Bahar, T. (2014). Personality descriptors ubiquitous across 12 languages. Journal of Personality and Social Psychology, 107, 199-216. https://doi.org/10.1037/a0036492.

Schmitt, D. P., Allik, J., McCrae, R. R., \& Benet-Martínez, V. (2007). The geographic distribution of Big Five personality traits: patterns and profiles of human self-description across 56 nations. Journal of Cross-Cultural Psychology, 38, 173-212. https://doi.org/ $10.1177 / 0022022106297299$.

Schmitt, D. P., Realo, A., Voracek, M., \& Allik, J. (2008). Why can't a man be more like a woman? Sex differences in Big Five personality traits across 55 cultures. Journal of Personality and Social Psychology, 94, 168-182. https://doi.org/10.1037/00223514.94.1.168.

Severance, L., Bui-Wrzosinska, L., Gelfand, M. J., Lyons, S., Nowak, A., Borkowski, W., et al. (2013). The psychological structure of aggression across cultures. Journal of Organizational Behavior, 34, 835-865. https://doi.org/10.1002/job.1873.

Suh, E. M. (2002). Culture, identity consistency, and subjective well-being. Journal of Personality and Social Psychology, 83, 1378-1391. https://doi.org/10.1037/00223514.83.6.1378.

Sullivan, E. A., \& Kosson, D. S. (2006). Ethnic and cultural variations in psychopathy. In C. J. Patrick (Ed.), Handbook of psychopathy (pp. 437-458). NY: Guilford.

Thalmayer, A. G., \& Saucier, G. (2014). The Questionnaire Big Six (QB6) in 26 nations: developing cross-culturally applicable Big Six, Big Five, and Big Two inventories. European Journal of Personality, 28, 482-496. https://doi.org/10.1002/per.1969.

Thalmayer, A. G., Saucier, G., Ole-Kotikash, L., Payne, D. L., \& Carlson, R. (2018). Indigenous personality structure in East and West Africa: Lexical studies of personality in Maa and Senoufo. Manuscript submitted for publication.

Tseng, W.-S. (2001). Handbook of cultural psychiatry. San Diego, CA: Academic Press.

Van de Gaer, E., Grisay, A., Schulz, W., \& Gebhardt, E. (2012). The reference group effect: an explanation of the paradoxical relationship between academic achievement and selfconfidence across countries. Journal of Cross-Cultural Psychology, 43, 1205-1228. https://doi.org/10.1177/0022022111428083.

Weisz, J. R., Suwanlert, S., Chaiyasit, W., \& Walter, B. R. (1987). Over-and undercontrolled referral problems among children and adolescents from Thailand and the United States: the Wat and Wai of cultural differences. Journal of Consulting and Clinical Psychology, 55, 719-726.

Yang, J., McCrae, R. R., Costa, P. T., Yao, S., Dai, X., Cai, T., et al. (2000). The cross-cultural generalizability of Axis-II constructs: an evaluation of two personality disorder assessment instruments in the People's Republic of China. Journal of Personality Disorders, 14, 249-263. https://doi.org/10.1521/pedi.2000.14.3.249. 
Zeinoun, P., Daouk-Öyry, L., Choueiri, L., \& Van de Vijver, F. J. (2017). A mixed-methods study of personality conceptions in the Levant: Jordan, Lebanon, Syria, and the West Bank. Journal of Personality and Social Psychology, 113(3), 453-465. https://doi.org/10.1037/ pspp0000148. 